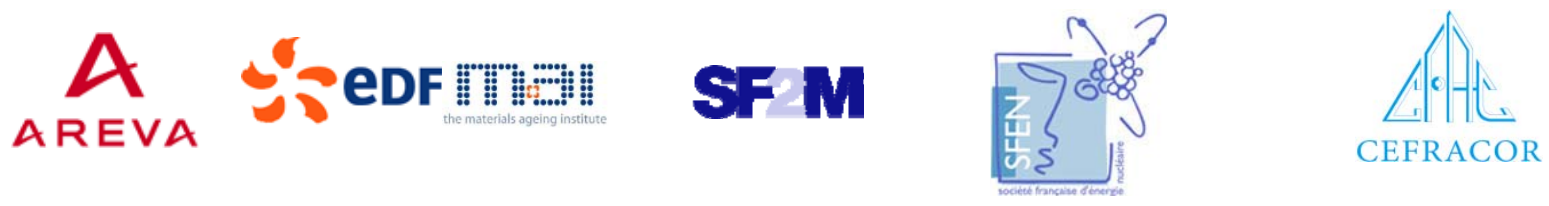

\section{MIN口S}

Centre of Excellence for Nuclear Materials

\section{Workshop}

Materials Innovation for Nuclear Optimized Systems
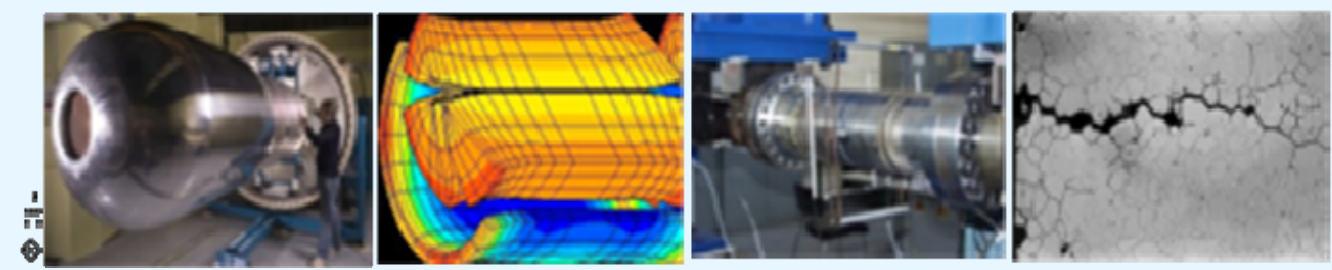

December 5-7, 2012, CEA - INSTN Saclay, France

\section{Jean-Luc BÉCHADE et al. CEA (France)}

New Characterizations at the MARS Beamline (SOLEIL Synchrotron Radiation)

Workshop organized by:

Christophe GALLÉ, CEA/MINOS, Saclay - christophe.galle@cea.fr Constantin MEIS, CEA/INSTN, Saclay - constantin.meis@cea.fr 


\title{
New Characterizations at the MARS Beamline (SOLEIL Synchrotron Radiation)
}

\author{
Jean-Luc BÉCHADE ${ }^{1}$, Denis MENUT ${ }^{1}$ Bruno SITAUD ${ }^{2}$, Sandrine SCHLUTIG ${ }^{2}$, \\ Isabelle LLORENS ${ }^{2}$, Marie-Laure LESCOAT ${ }^{1}$, Joel RIBIS ${ }^{1}$, Nicolas JONQUĖRES ${ }^{3}$, \\ Dominique LETERME ${ }^{4}$, \\ ${ }^{1}$ CEA-DEN-DMN, Service de Recherches Métallurgiques Appliquées, SRMA (Saclay, France) \\ 'Synchrotron SOLEIL, Ligne de MARS (Saint Aubin, France) \\ ${ }^{3}$ CEA-DEN-DM2S, Service d'Etudes Mécaniques et Thermiques, SEMT (Saclay, France) \\ ${ }^{4}$ CEA-DEN-DANS, Service de Soutien aux Projets, à la Sécurité et à la Sûreté, SP2S (Saclay, France)
}

\begin{abstract}
MARS (Multi-Analyses on Radioactive Samples) is the X-ray bending magnet beamline of the French synchrotron facility SOLEIL dedicated to the study of radioactive matter by means of a multitechnique equipment [1].
\end{abstract}

The MARS beamline is the fourth dedicated beamline for studying radionuclides in Europe (after the ROBL beamline at ESRF (Grenoble, France), the INE beamline at ANKA (Karlsruhe, Germany) and the microXAS beamline at SLS (Villingen, Switzerland) and aims at extending the possibilities of synchrotron based $\mathrm{X}$-ray characterizations towards a wider variety of radioactive elements ( $\alpha, \beta, \gamma$ and $\mathrm{n}$ emitters). Thus, its specific and innovative infrastructure has been optimized to carry out analyses on radioactive materials with global activities up to $18.5 \mathrm{GBq}$ per sample [2]. Particularly, it offers unique possibilities for studying $\gamma$ and neutrons emitters' samples with an activity up to $2 \mathrm{GBq}$. Nevertheless, such a possibility supposes to obtain special authorizations from French safety authorities (ASN) based on specific technical innovations to assure the confinement of samples and to reduce the dose rate during their manipulation on the beamline.

This beamline, which has been built thanks to a close partnership and support by the CEA, has been designed to provide X-rays in the energy range of $3.5 \mathrm{keV}$ to $35 \mathrm{keV}$. Three main techniques are progressively proposed on MARS beamline: transmission and high-resolution powder X-ray diffraction (respectively TXRD and HRXRD), X-ray absorption spectroscopy (XAS) and X-ray fluorescence (XRF) [3].

After the preliminary experiences performed in 2009-2010 on un-irradiated samples [1, 3, 4], this presentation deals with recent results obtained at the MARS beamline, thanks, (i) to very powerful and useful improvements brought to the experimental set-up of the beamline (especially High Resolution diffractometer, fig. 1) and (ii) to various materials irradiated at high doses with ions (ODS up to $200 \mathrm{dpa}$ ) and also Zr based alloys irradiated with neutrons in Pressurized Water Reactors up to 5 PWR cycles.

The results obtained by $X$ ray Diffraction on secondary phases evolutions as a function of irradiation doses for both ODS and Zr based alloys will be exposed, along with the very first XAS experiences performed on ODS materials.

Finally, future prospects and main objectives concerning the evolution of the beamline for our program on irradiated materials will be discussed; for example the milestone for 2013 concerning the analysis on ODS irradiated at high doses with neutrons. 


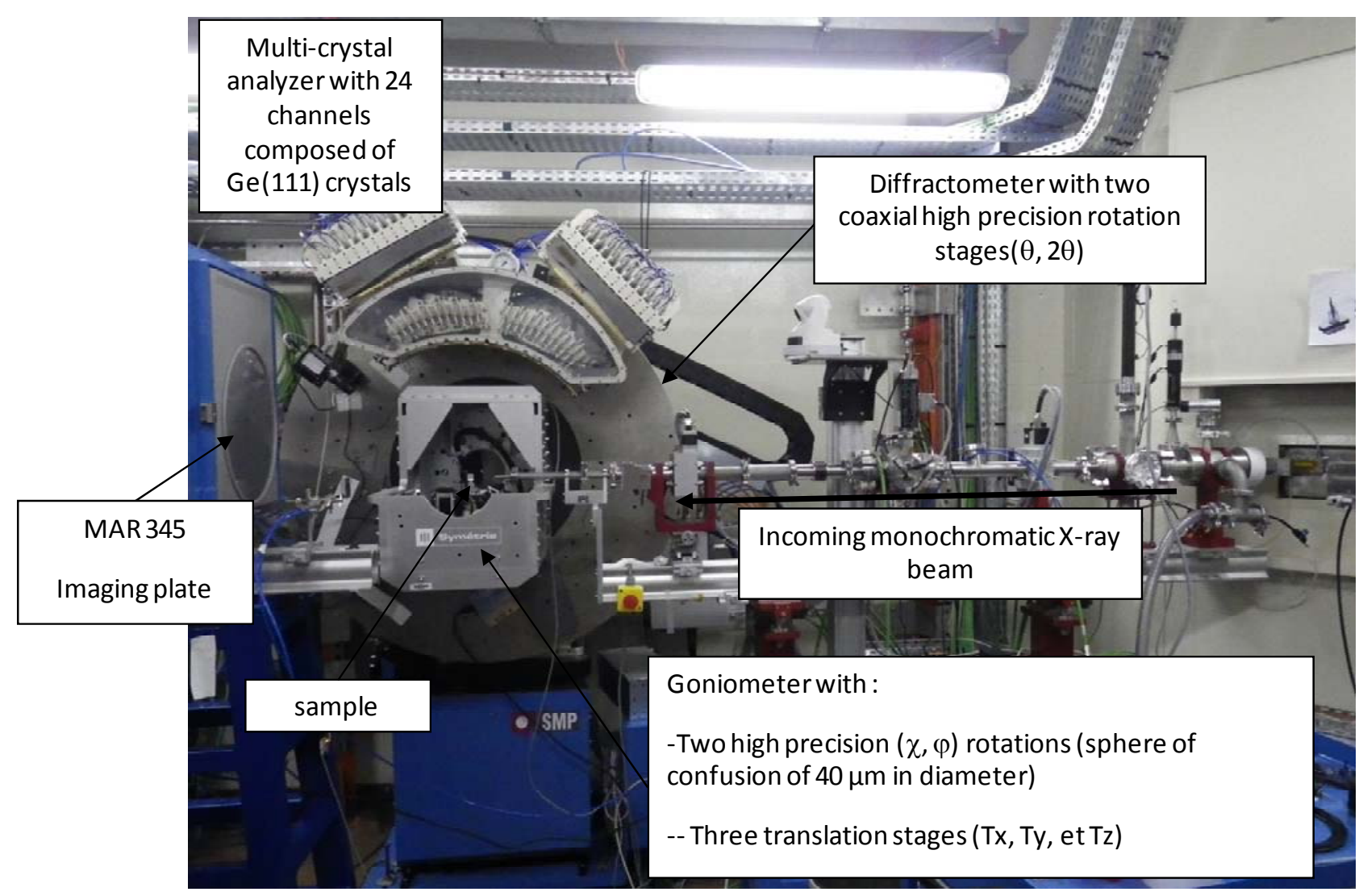

Fig. 1: High Resolution X Ray Diffractometer at the MARS beamline.

\section{References}

[1] B. Sitaud, P.L. Solari, S. Schlutig, I. Llorens, H. Hermange, Characterization, of radioactive materials using the MARS beamline at the synchrotron SOLEIL. Journal of Nuclear Materials 425 (2012) 238-243.

[2] P.L. Solari, S. Schlutig, H. Hermange and B. Sitaud. Journal of Physics: Series 190 (2009) 012042.

[3] S. Schlutig, P.L. Solari, H. Hermange, B. Sitaud, Basic Actinide Science and Materials for Nuclear Applications, 2010. Materials Research Society Symposium Proceedings, 1264, p.131-136.

[4] J.-L. Béchade, D. Menut, M.-L. Lescoat, B. Sitaud, S. Schlutig, P.L. Solari, I. Llorens, H. Hermange, Y. de Carlan, J. Ribis, L. Toualbi, Application of synchrotron radiation to analyze the precipitation in ODS materials before irradiation in $\mathrm{Fe}-9 \% \mathrm{Cr}$ single grain of powder and consolidated Fe-18\%Cr. Journal of Nuclear Materials 428 (2012) 183-191. 


\section{MINDS}

\section{New characterizations at the MARS* beamline (SOLEIL synchrotron radiation)}

J.-L. Béchade ${ }^{1}$, D. Menut ${ }^{1}$, B. Sitaud ${ }^{2}$, S. Schlutig ${ }^{2}$, I. Llorens ${ }^{2}$, M.-L. Lescoat ${ }^{1}$, J. Ribis ${ }^{1}$, N. Jonquères ${ }^{3}$, D. Leterme ${ }^{4}$,

1CEA-DEN, Service de Recherches Métallurgiques Appliquées 'Synchrotron SOLEIL, Ligne de MARS

${ }^{3}$ CEA-DEN, Service d'Etudes Mécaniques et Thermiques

${ }^{4}$ CEA-DEN, Service de Soutien aux Projets, à la Sécurité et à la Sûreté

\section{* Multi Analyses on Radioactive Samples}




\section{CQ BRIEF OVERVIEW OF THE MARS BEAMLINE}

\section{$\because$ MINDS}

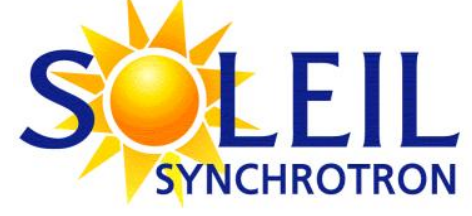

National synchrotron facility, third generation source

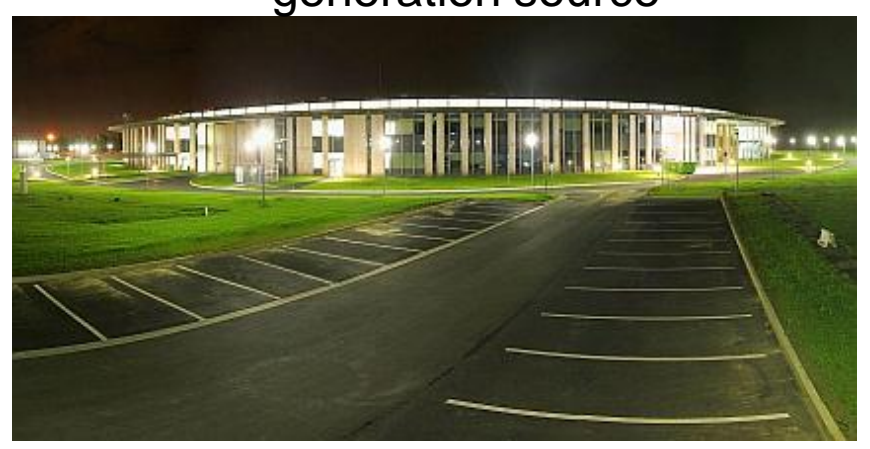

\begin{tabular}{|c|c|}
\hline Nominal Energy & $2.75 \mathrm{GeV}$ \\
\hline Circumference & $354 \mathrm{~m}$ \\
\hline Emittance H & $4 \mathrm{~nm} \cdot \mathrm{rad}$ \\
\hline Current Intensity & $\begin{array}{c}400 \mathrm{~mA} \\
(430 \mathrm{~mA} \text { in 2012) }\end{array}$ \\
\hline
\end{tabular}

29 beamlines foreseen

24 beamlines opened to users on $2^{\text {nd }}$ semester 2012

( $1^{\text {st }}$ beam in december 2008$)$

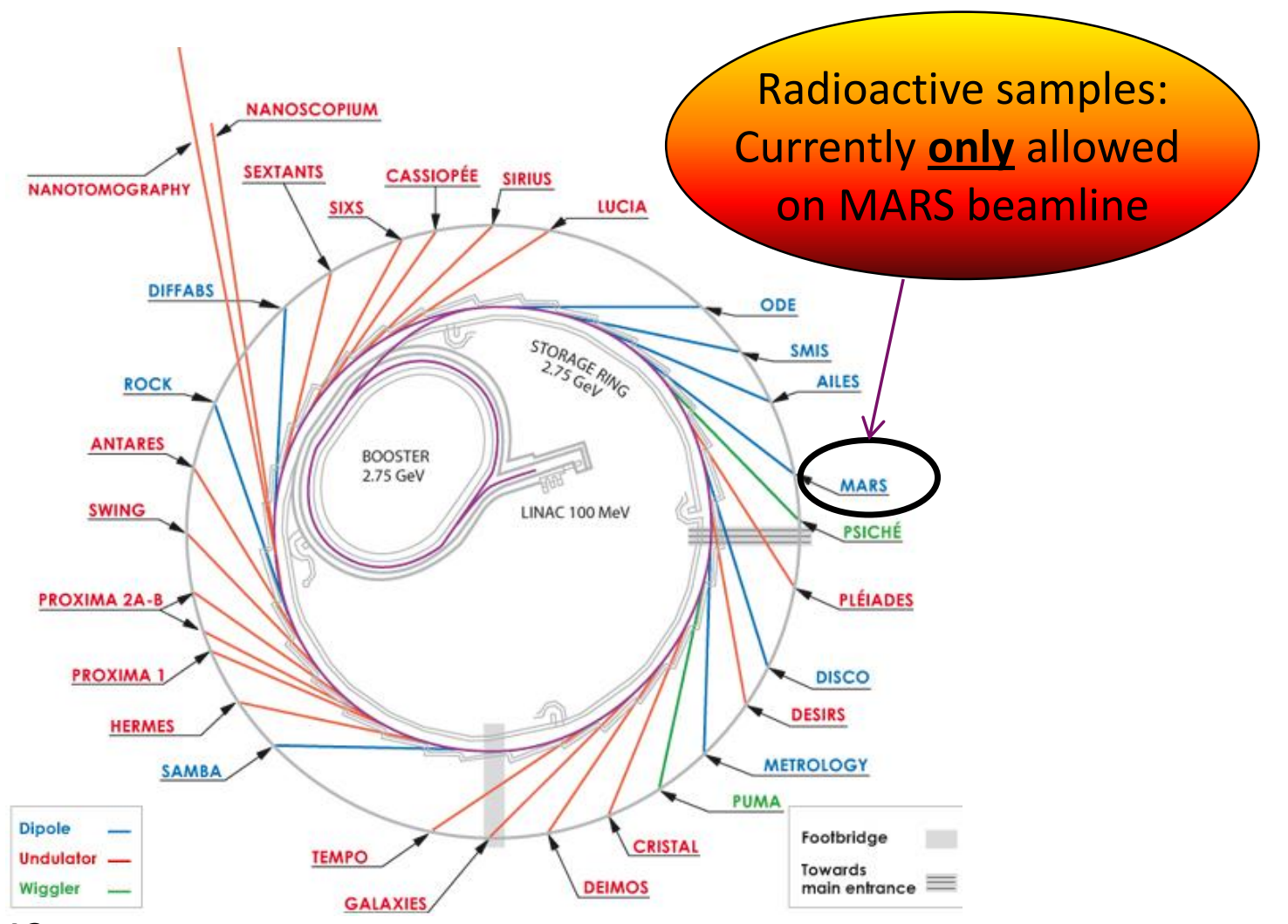




\section{Ceב MARS A DEDICATED X-RAY BEAMLINE FOR RADIOACTIVE MATTER}

MINDS

Multi-Analysis on Radioactive Sample (MARS) beamline, at synchrotron SOLEIL, is fully dedicated to advanced structural and chemical characterizations of radioactive matter (solid or liquid).

A multi-technique beamline infrastructure and optics optimized for : Absorption spectroscopy, Fluorescence, Diffraction

\section{Energy range of the X-ray beam : 3.5 to $35 \mathrm{keV}$}

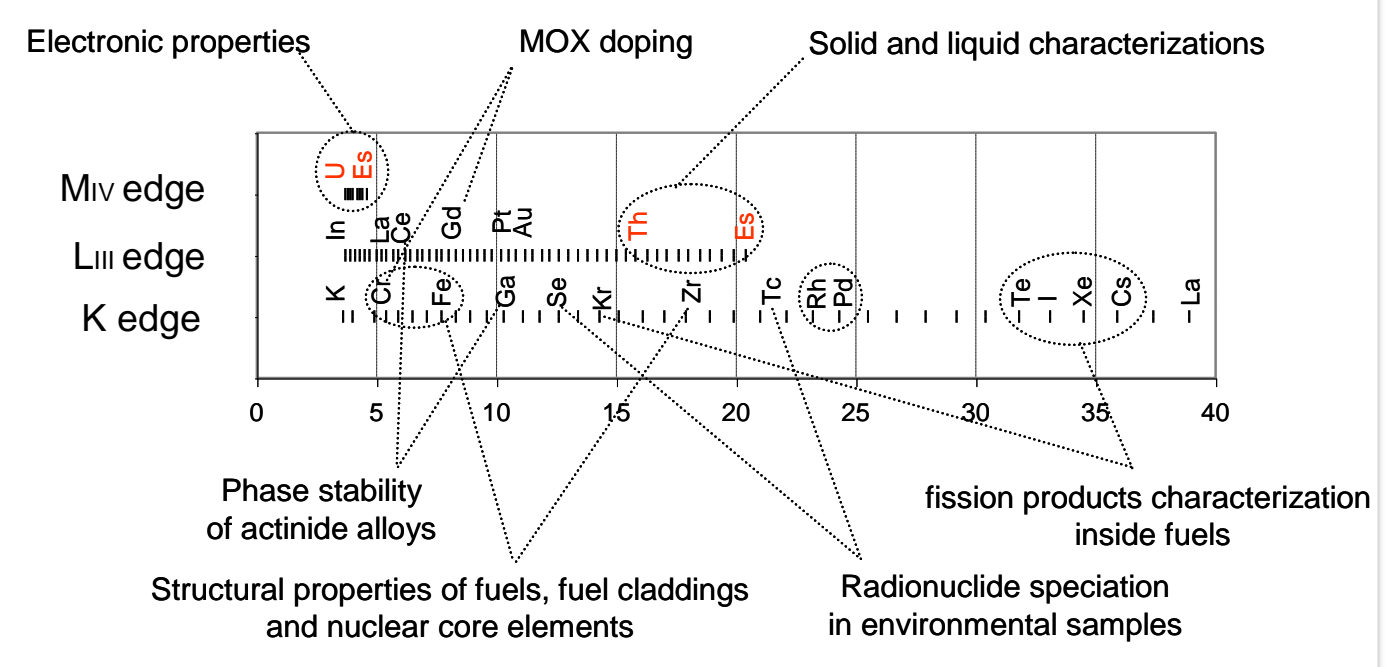

Sample maximum activity on MARS beamline :

$18.5 \mathrm{GBq}$ per sample for $\alpha$ - and $\beta$-emitters

2.0 GBq per sample for $\gamma$ - and n-emitters 


\section{CeăLAYOUT OF THE MARS BEAMLINE (SIDE VIEW)}

\section{$\because$ MINDS}

A "hot" beamline inside a standard synchrotron building Maincontrol
room
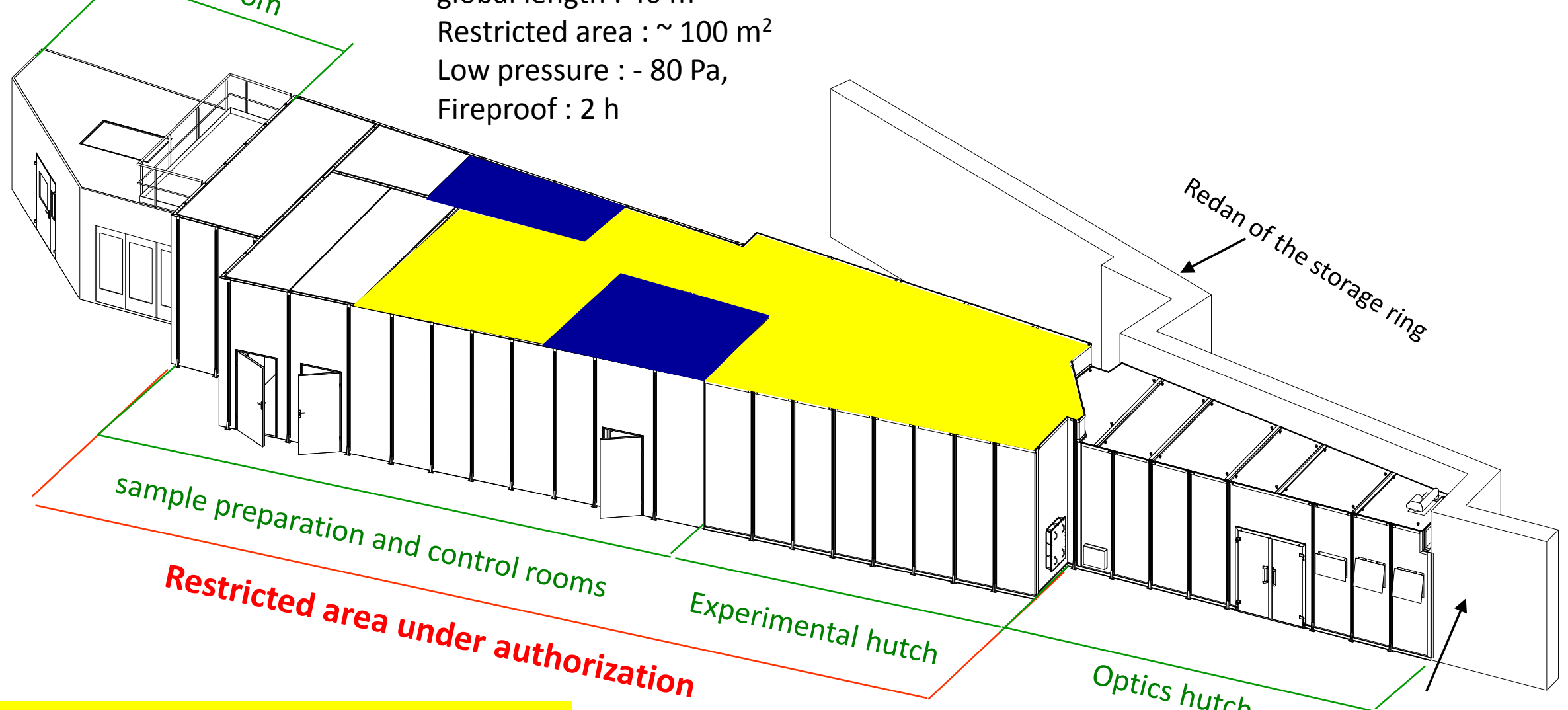

Max. dose rate limitation :

inside $2 \mathrm{mSv} / \mathrm{h}$ and outside $0.5 \mu \mathrm{Sv} / \mathrm{h}$ 


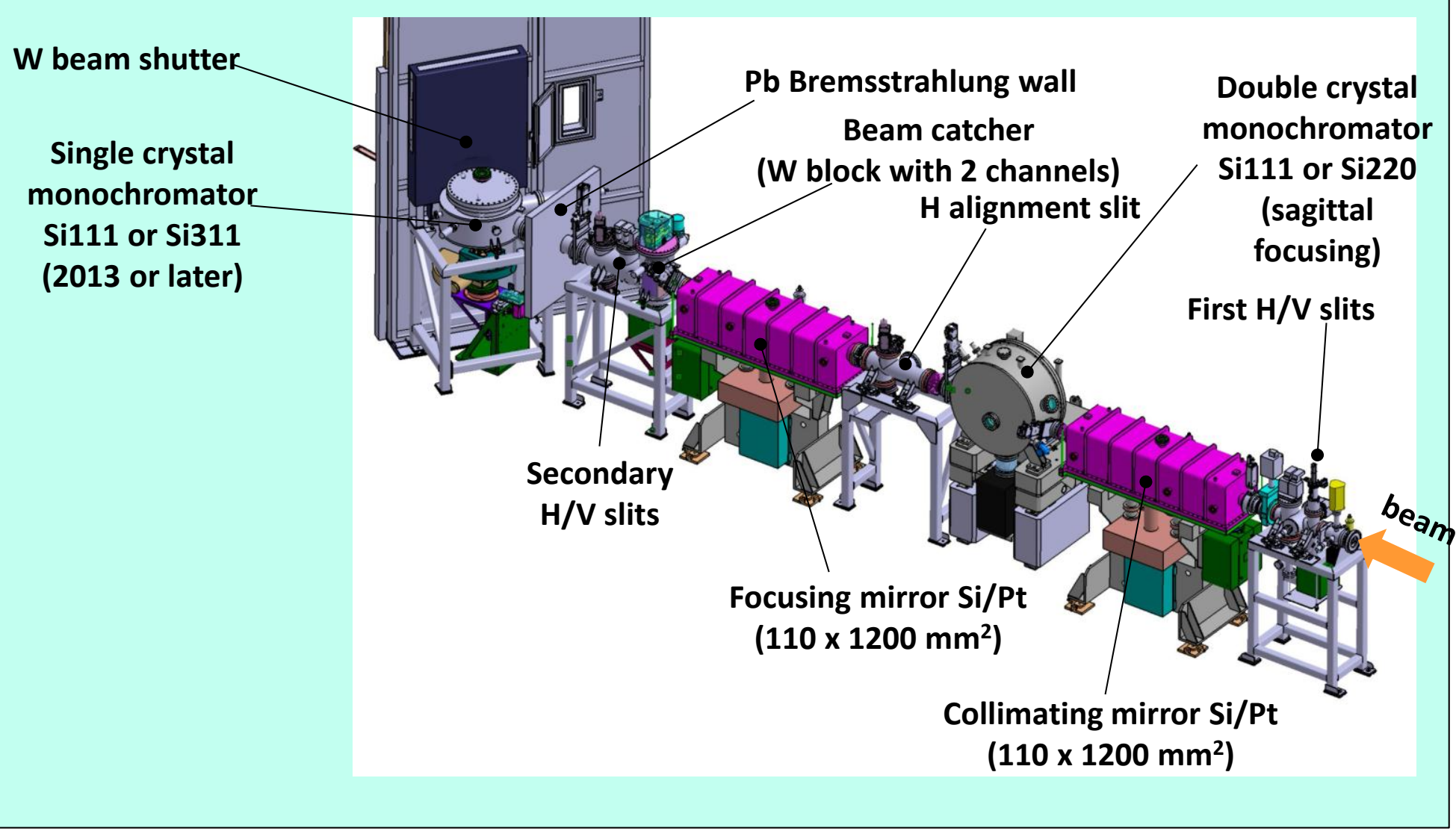




\section{MIN口S}

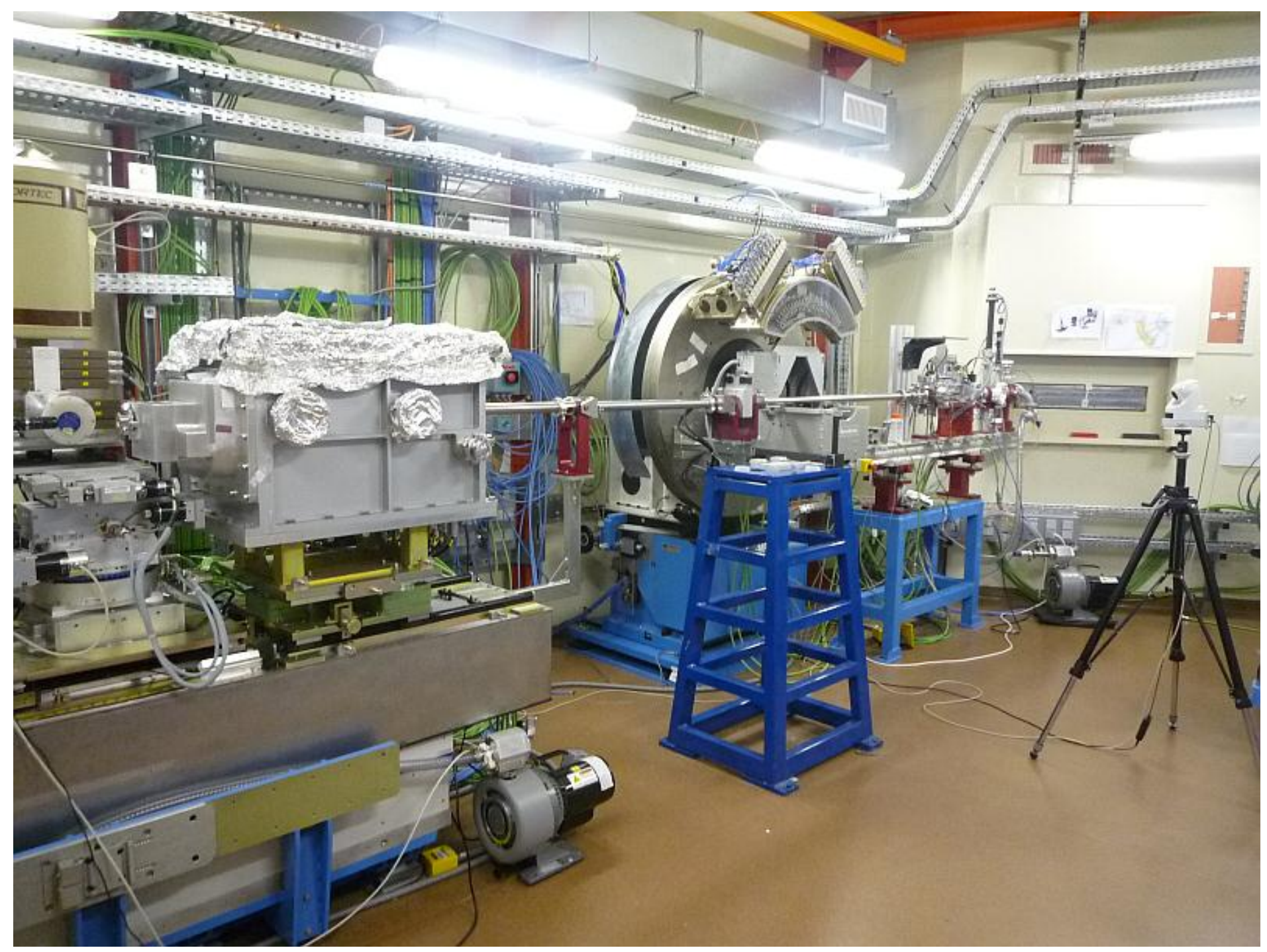


<-rMonochromatic branch: Standard spot size $(\mathrm{HxV}) \sim 300 \times 200 \mu \mathrm{m}^{2}$ Flux $5 \times 10^{11} \mathrm{ph} / \mathrm{s}$ at 17 keV with $\mathrm{Si}(220)$ and I = $400 \mathrm{~mA}$
Standard Absorption station XAS, T-XRD, XRF

Opened to users : 2010
High Resolution Diffraction station HR-XRD with 4 circles diffractometer

Opened to users : 2011

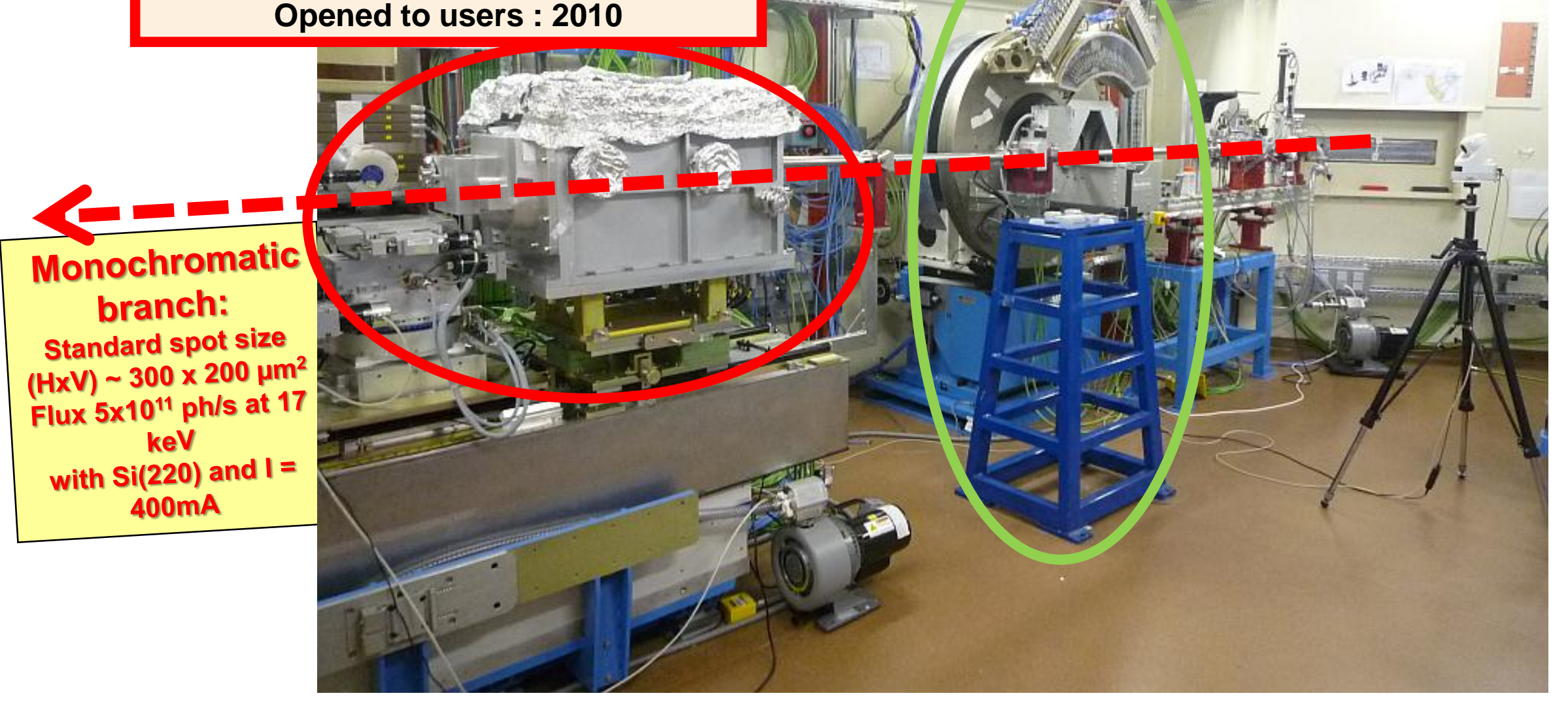




\section{EXAMPLES OF MATERIALS FOR NUCLEAR APPLICATIONS}

\section{MINDS Fuel cladding materials studied at the Nuclear Energy Division:}

$\mathrm{Zr}$ based alloys for Gen2\&3 reactors (PWR)

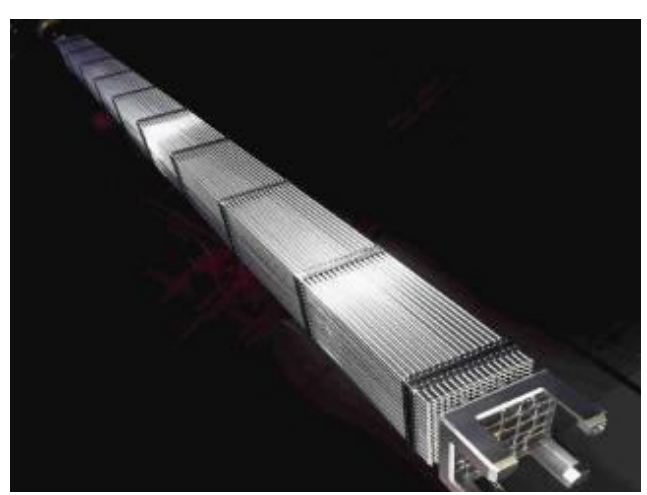

$\mathrm{M}^{\mathrm{TM}}: \mathrm{Zr}-1 \% \mathrm{Nb}$ corrosion behaviour largely improved thanks to $\mathrm{Nb}$ addition

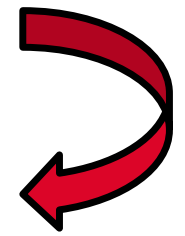

ODS steels for Gen4 reactors (SFR)

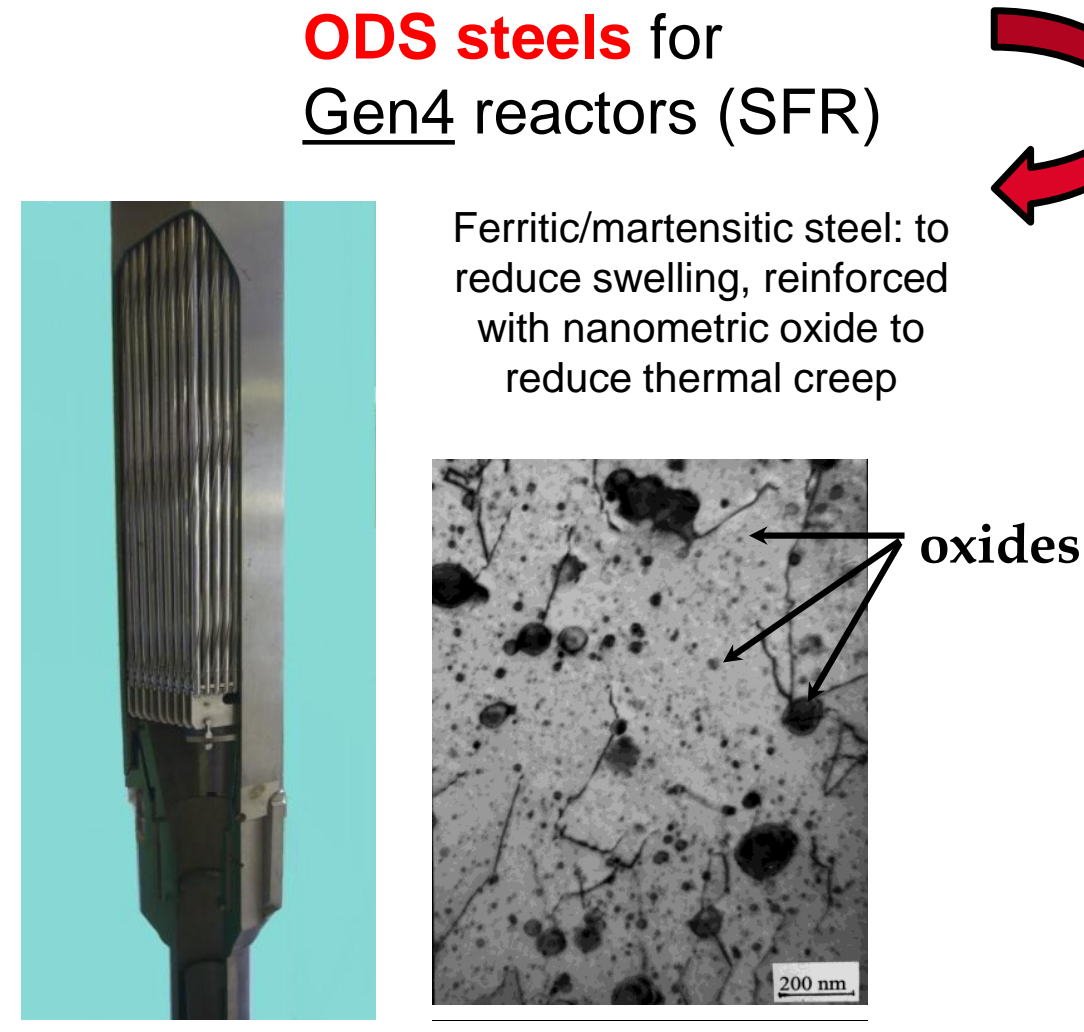

Ferritic/martensitic steel: to reduce swelling, reinforced with nanometric oxide to reduce thermal creep

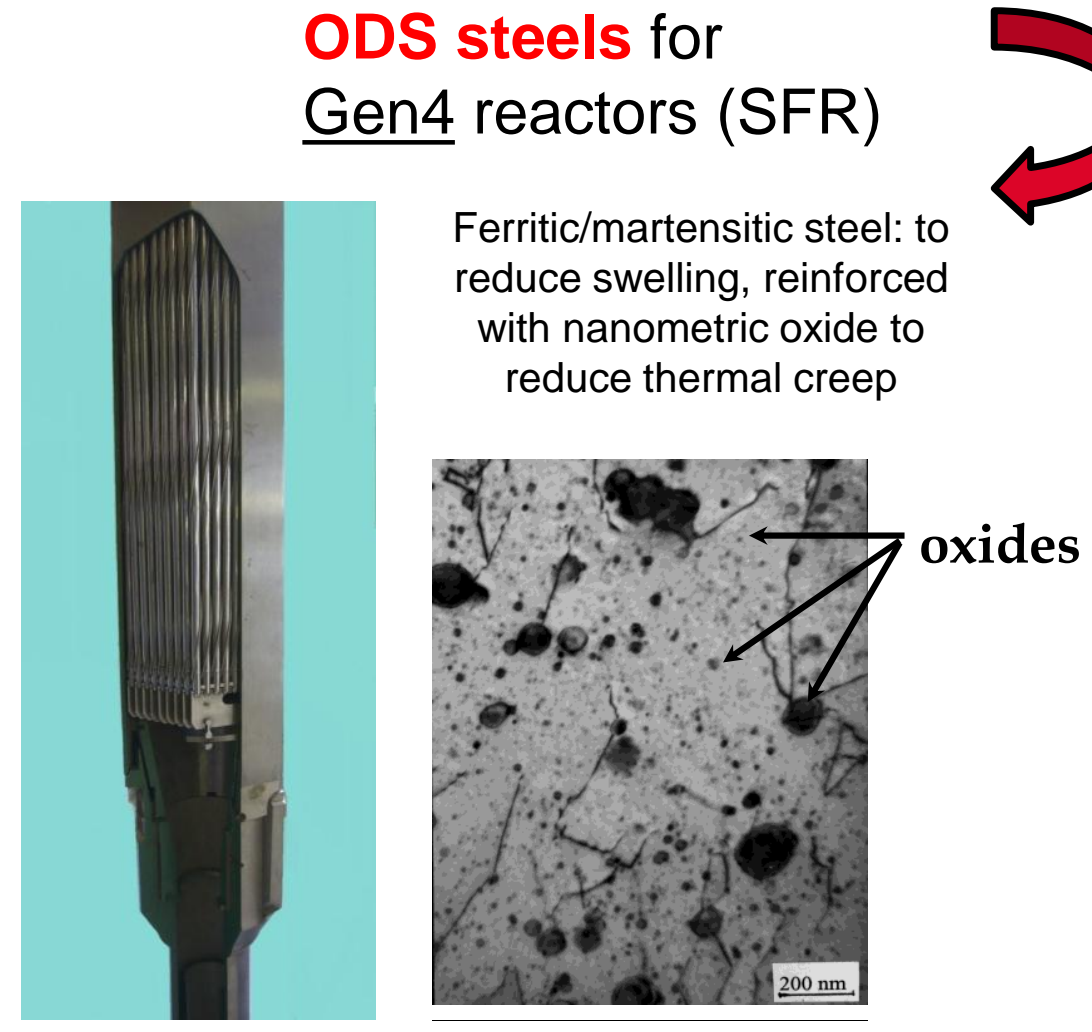

$\beta-\mathrm{Nb}:$ natives + accelarated precipitation under irradiation

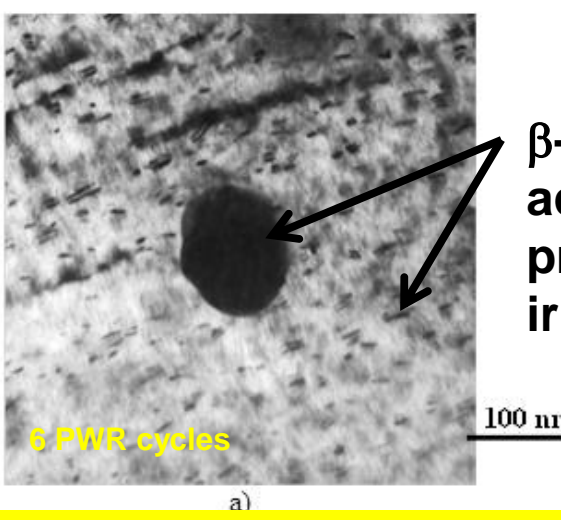

Same goal for both studies: secondary phases (less than $0.5 \%$ vol. fraction) evolutions under irradiation 

PWR CYCLES (up to $11.10^{25} \mathrm{n} / \mathrm{m}^{2} @ 330^{\circ} \mathrm{C}$ )

\section{MIN口S}

\section{XAS station used: Transmission X-Ray Diffraction}

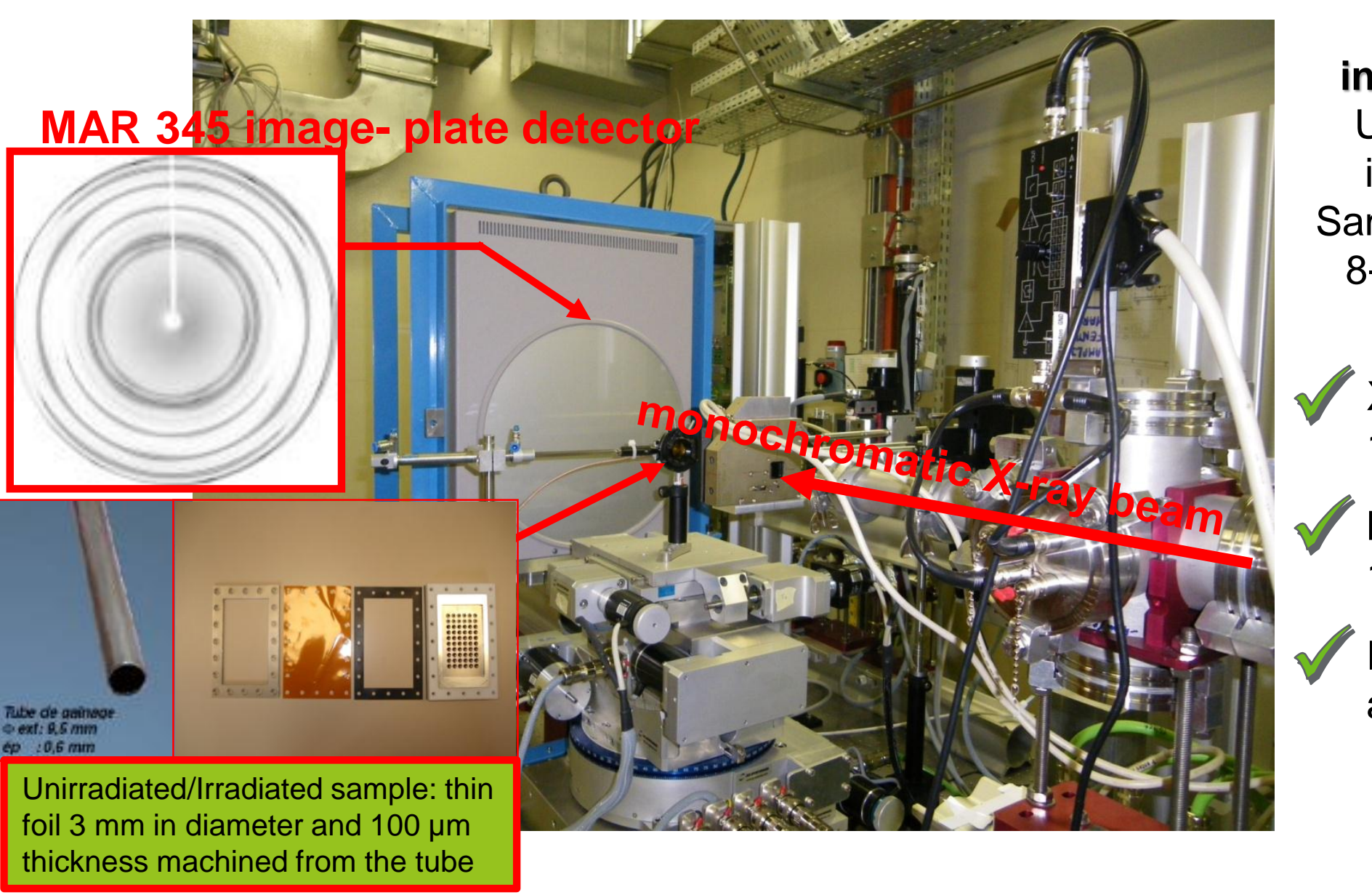

XRD analysis in transmission mode Using a 2-dimensions image-plate detector Sample positionned on an 8-axis motorized stage

$\mathrm{X}$-ray beam energy : $17.038 \mathrm{keV}$

Beam size $(\mathrm{H} \times \mathrm{V})$ : $100 \times 100 \mu \mathrm{m}^{2}$

Exposure time : about $240 \mathrm{~s}$ 


\section{$\because$ MINDS}

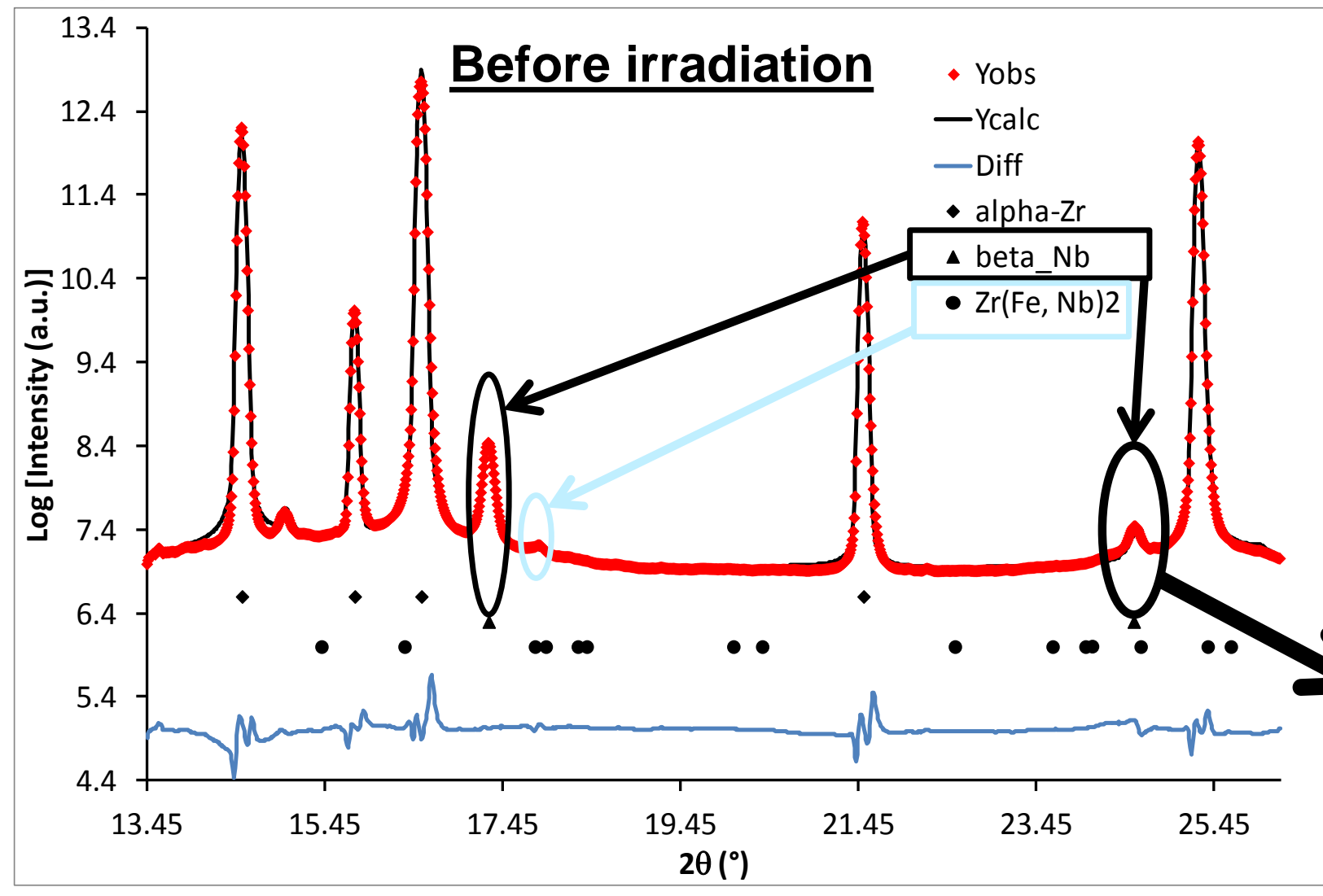

The $\beta$-Nb diffraction peak after irradiation is the convolution of 2 contributions :

- Native $\beta-\mathrm{Nb}$ precipitates.

- Radiation-enhanced $\beta-\mathrm{Nb}$ particles 


\section{RESULTS (2/2)}

\section{$\because$ MINDS}

\section{Analyses of the initial $\beta-\mathrm{Nb}$ precipitates vs irradiation dose}

Consistent with TEM analyses $(S$. Doriot, M. Griffith, V. Shishov, ASTM 1996) but with higher statistic and better accuracy

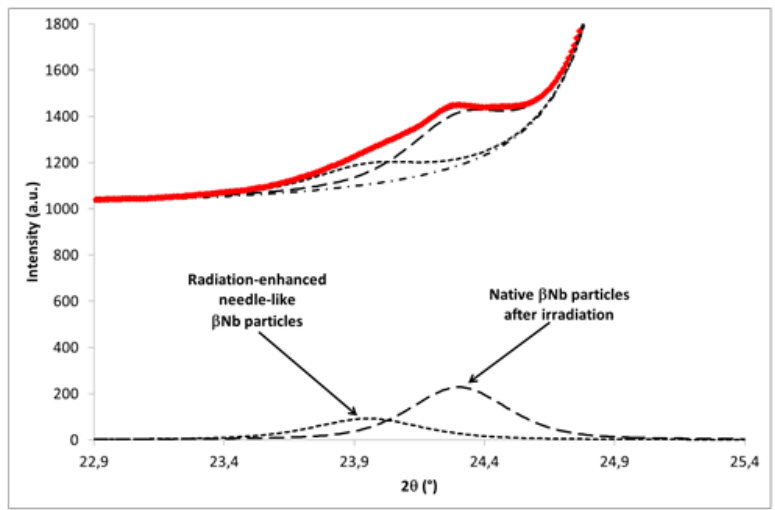

Example of deconvolution: 2 PWR cycles
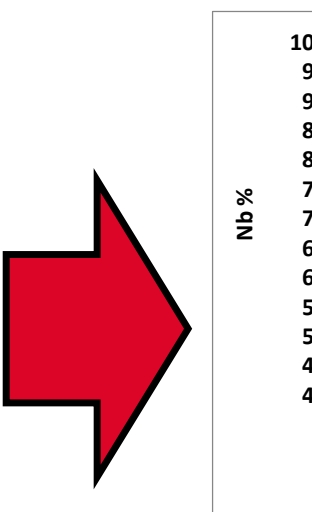

$\mathrm{Nb}$ content in the native precipitates

$>$ Analyses of the radiation-enhanced $\beta$-Nb particles vs irradiation dose

Data not accessible by TEM: nanometric particles (less than 0.5 vol. fraction) can be analyzed using XRD at MARS beamline

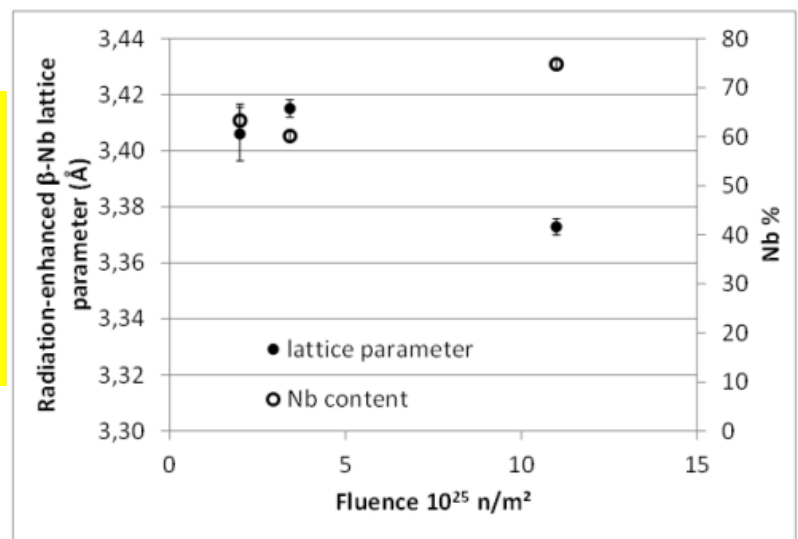

- Journal of Nuclear Materials submitted in octobre 2012, conf. Size and Strain VI 2011

- Paper accepted at ASTM $2013,17^{\text {th }}$ International Symposium on "Zirconium in the Nuclear Industry", February 03-07, 2013, Taj Krishna, Hyderabad, India CEA - DEN 


\section{HIGH RESOLUTION POWDER DIFFRACTION STATION (HR-XRD)}

\section{$\because \mathrm{MINDS}$}

Scientific applications of HR-XRD can broadly classified as:

- solving and refining of complex crystal structures,

- measurements of residual stress, textures,

- microstructure characterizations from analysis of peak shapes,....

Goniometer rotations and translations

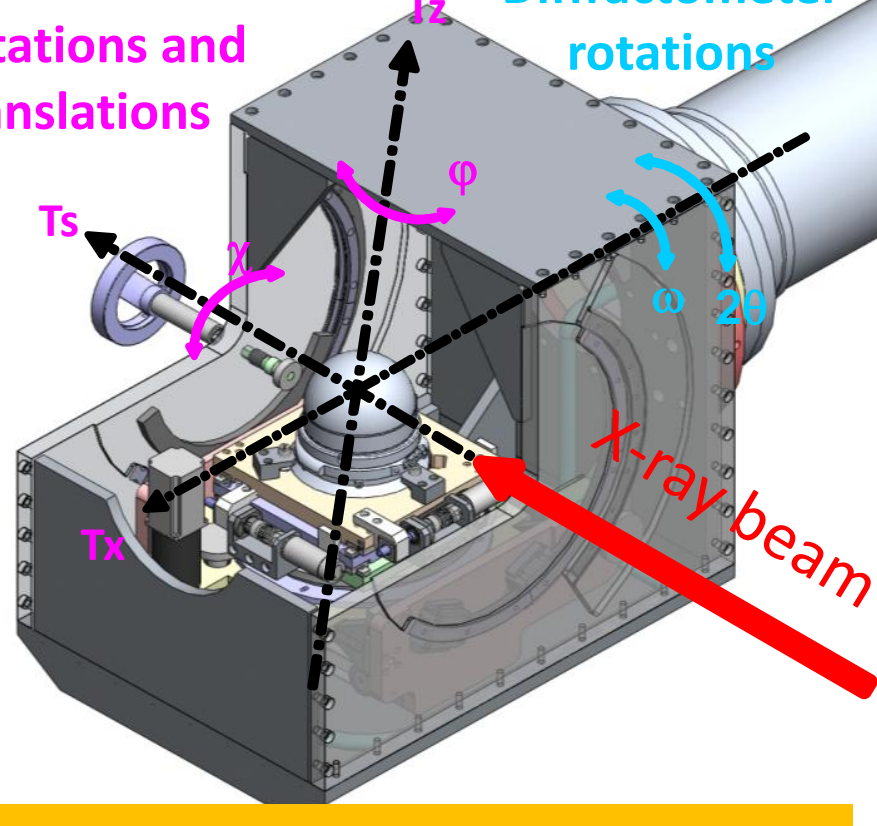

2 - A goniometer (CEA/DEN, Symétrie)

With high precision, weight capacity of $5 \mathrm{Kg}$, a sphere of confusion of $\underline{40 \mu \mathrm{m}}$ between 3 rotation axes, $\Omega, \chi$ and $\varphi$

CEA - DEN
3 - A detection system (CEA/DEN, COMAT)

24 crystals analyzer $\mathrm{Ge}(111$ crystals)

$\rightarrow$ multi-crystal analyzer stage concept [Hodeau 1998] : 2 systems of symmetrical 12 analyzers mounted on the $2 \theta$ arms $\left(67.4^{\circ}\right.$ ) $\rightarrow$ decrease the background radiation coming from high radioactive samples

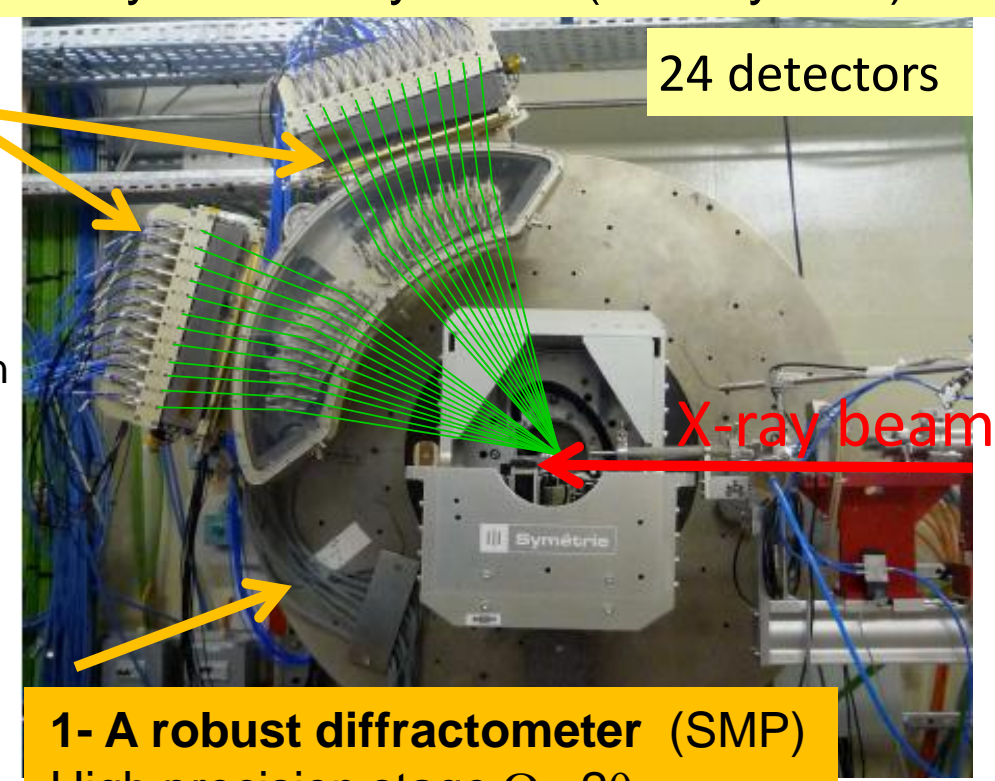

High precision stage $\Omega, 2 \theta$ 


\section{CO TYPICAL HIGH RESOLUTION DIFFRACTION PATTERN: APPLICATION TO GROWTH UNDER IRRADIATION FOR Zr ALLOYS}

\section{$\because \mathrm{MINDS}$}

Comparison between the diffraction peak from the (100) reflection of the standard NIST LaB6 powder recorded at $17.038 \mathrm{keV}$ with the PM1 detector of the multi-crystal analyzer and with a MAR345 detector

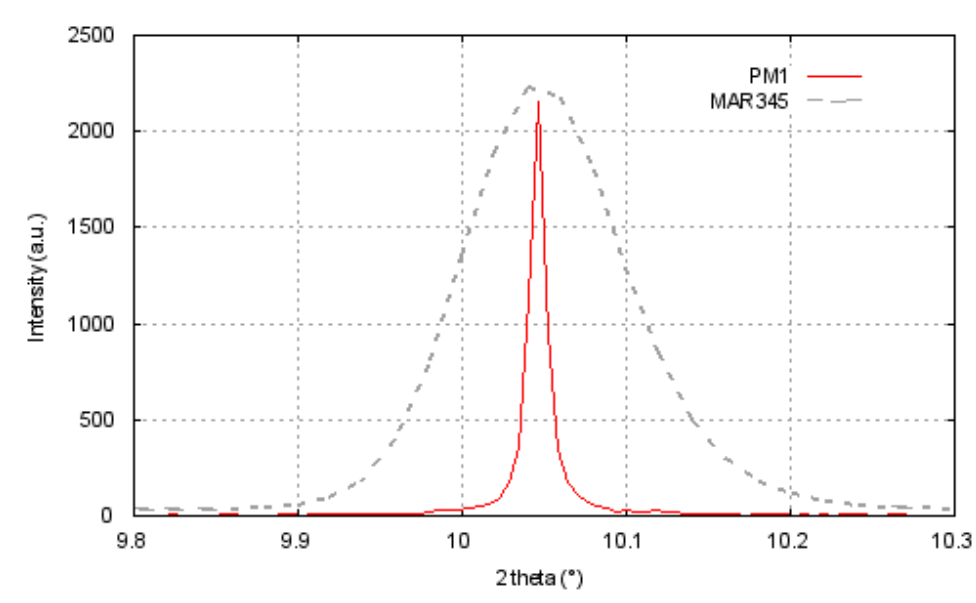

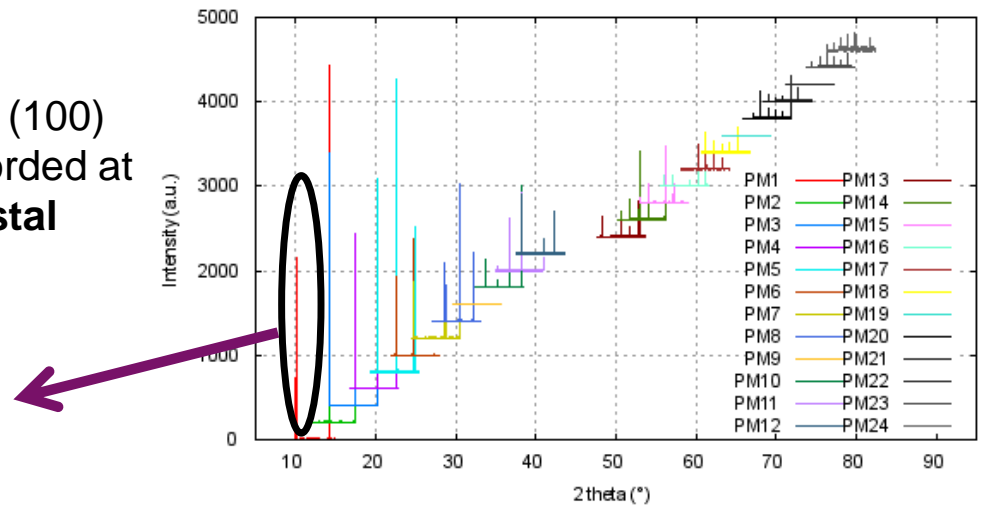

$=>$ Typically the FWHM linewidth is reduced by a factor of 10 with the use of the multi-analyser (FWHM are below $0.01^{\circ}$ ) compared to the MAR345 result.

\section{Application to irradiation defects in $\mathrm{Zr}$ based alloys}

$<\mathrm{C}>$ loops density, directly linked to radiation induced growth of $\mathrm{Zr}$ alloys

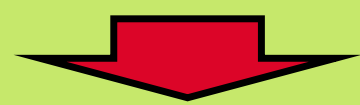

Broadening of diffraction peaks ( micro-deformation) $=>$ work in progress 


\section{2 - ODS FERRITIC/MARTENSITIC STEELS FOR SFR}

\section{$\because \mathrm{MINDS}$}

\section{ODS alloys studied}

Fe-9Cr-0.1C-1W + $10 \mathrm{wt} \% \mathrm{Y}_{2} \mathrm{O}_{3}$ as modelling alloy at powder state

$\mathrm{Fe}-18 \mathrm{Cr}-1 \mathrm{~W}-0.4 \mathrm{Ti}+0.56 \mathrm{wt} \% \mathrm{Y}_{2} \mathrm{O}_{3}$ as consolidated samples

CEA fabrication/ODS Project

Y De Carlan ,J. Nucl. Mater. 386-388 (2009) 430-432.

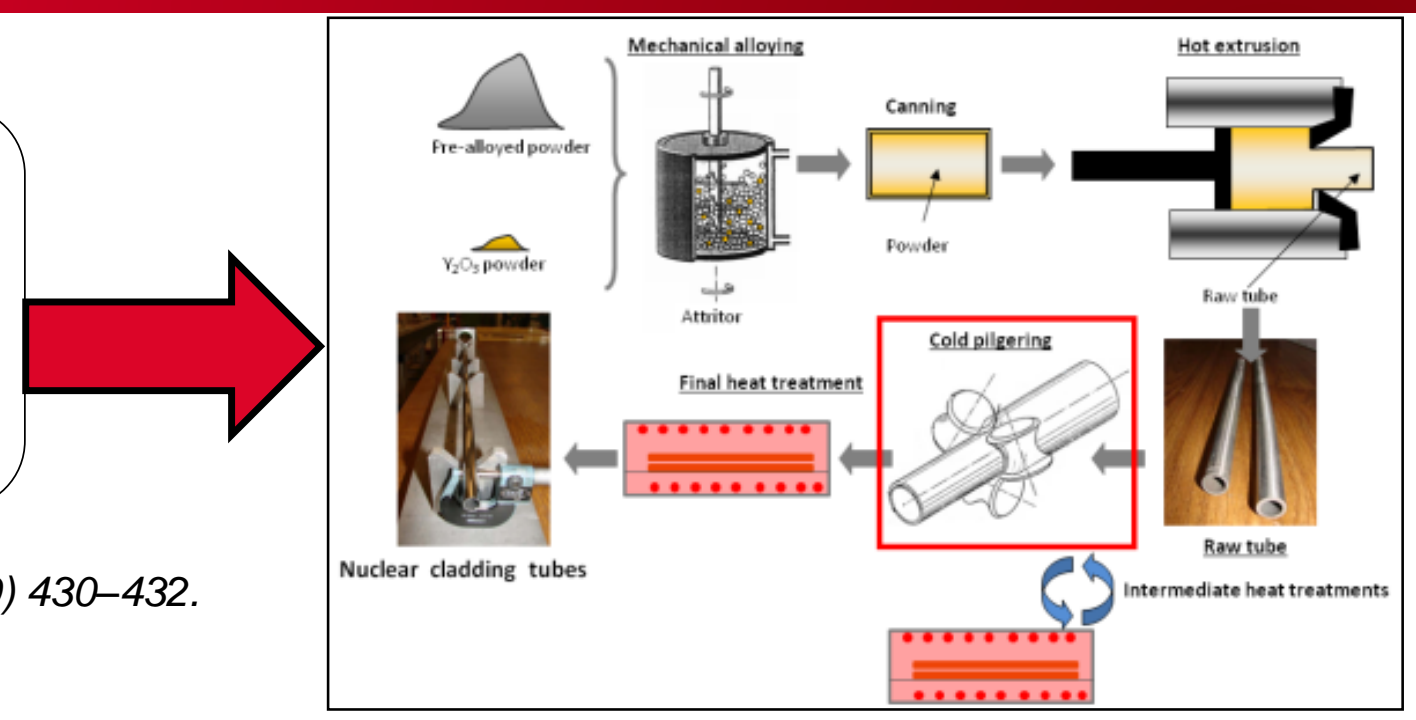

Characterization of the nano-oxide dispersion
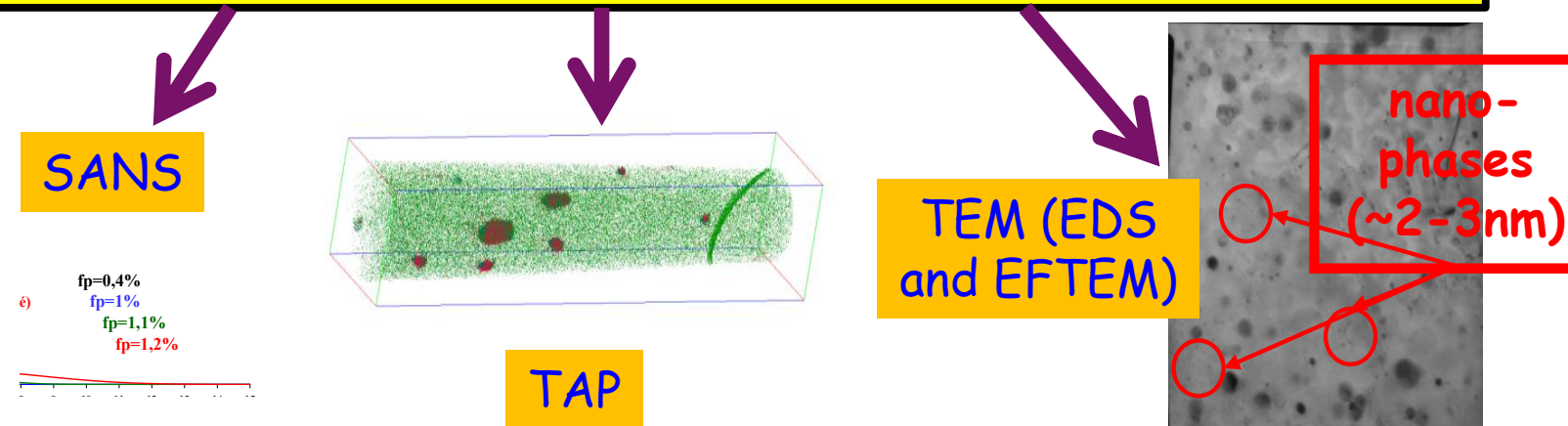

TEM (EDS and EFTEM)

nm)

\section{TAP}

What about the crystallographic structure, local environment during the process and before/after irradiation?

J-L Béchade et al. Journal of Nuclear Materials 428 (2012) 183-191

CEA - DEN 


\section{¿MIN口S XAS station used: Transmission X-Ray Diffraction}

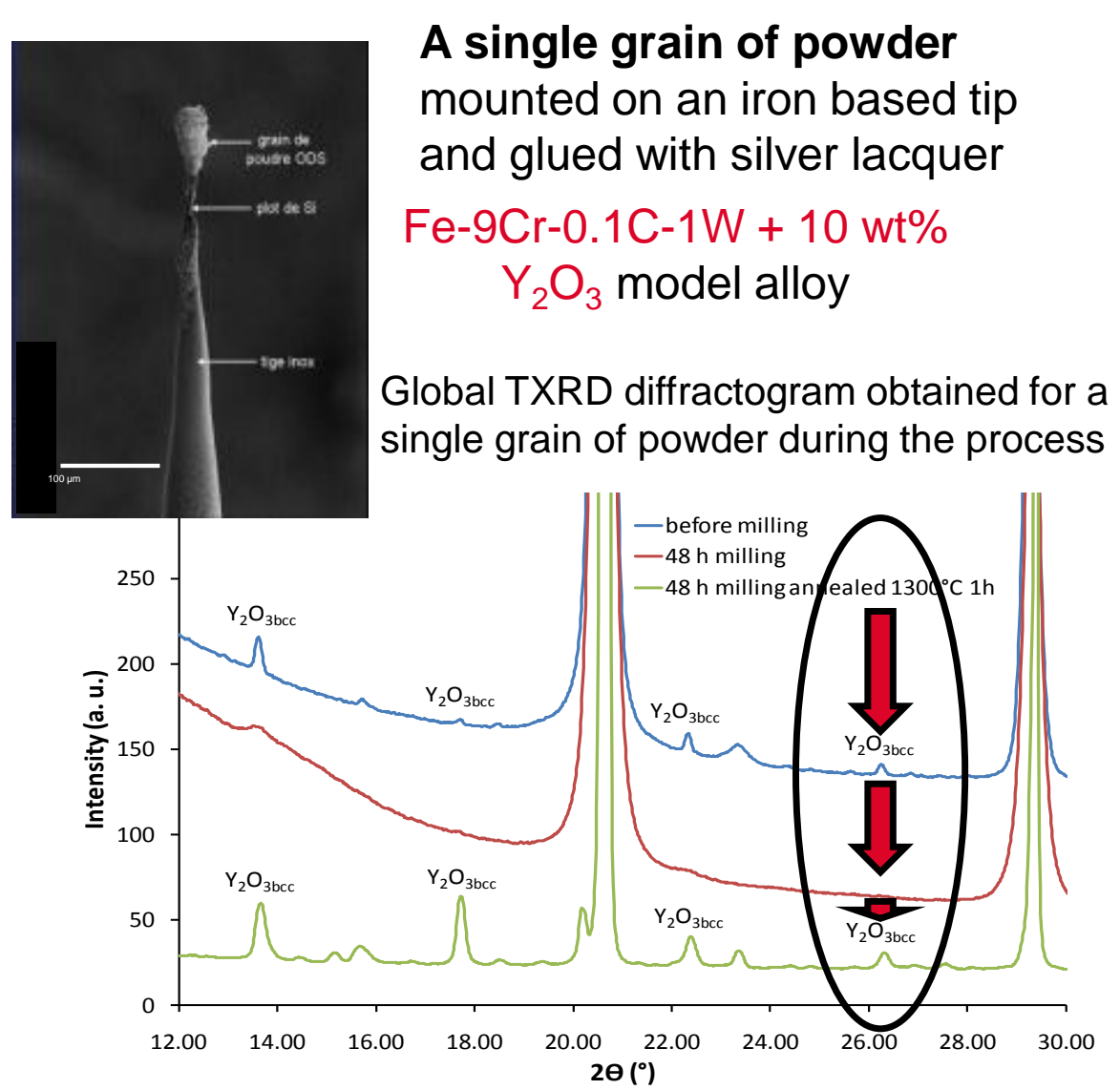

Precipitation happens during the consolidation process with thermal annealing $=>\mathrm{Y}_{2} \mathrm{O}_{3 \mathrm{bcc}}$ cristallite sizing $\sim 20 \mathrm{~nm}$

(L Toualbi et al. JNM 2012)
Consolidated thick rectangular bar annealed at $1300^{\circ} \mathrm{C} 1 \mathrm{~h}$

$\mathrm{Fe}-18 \mathrm{Cr}-1 \mathrm{~W}-0.4 \mathrm{Ti}+0.56 \mathrm{wt} \% \mathrm{Y}_{2} \mathrm{O}_{3}$

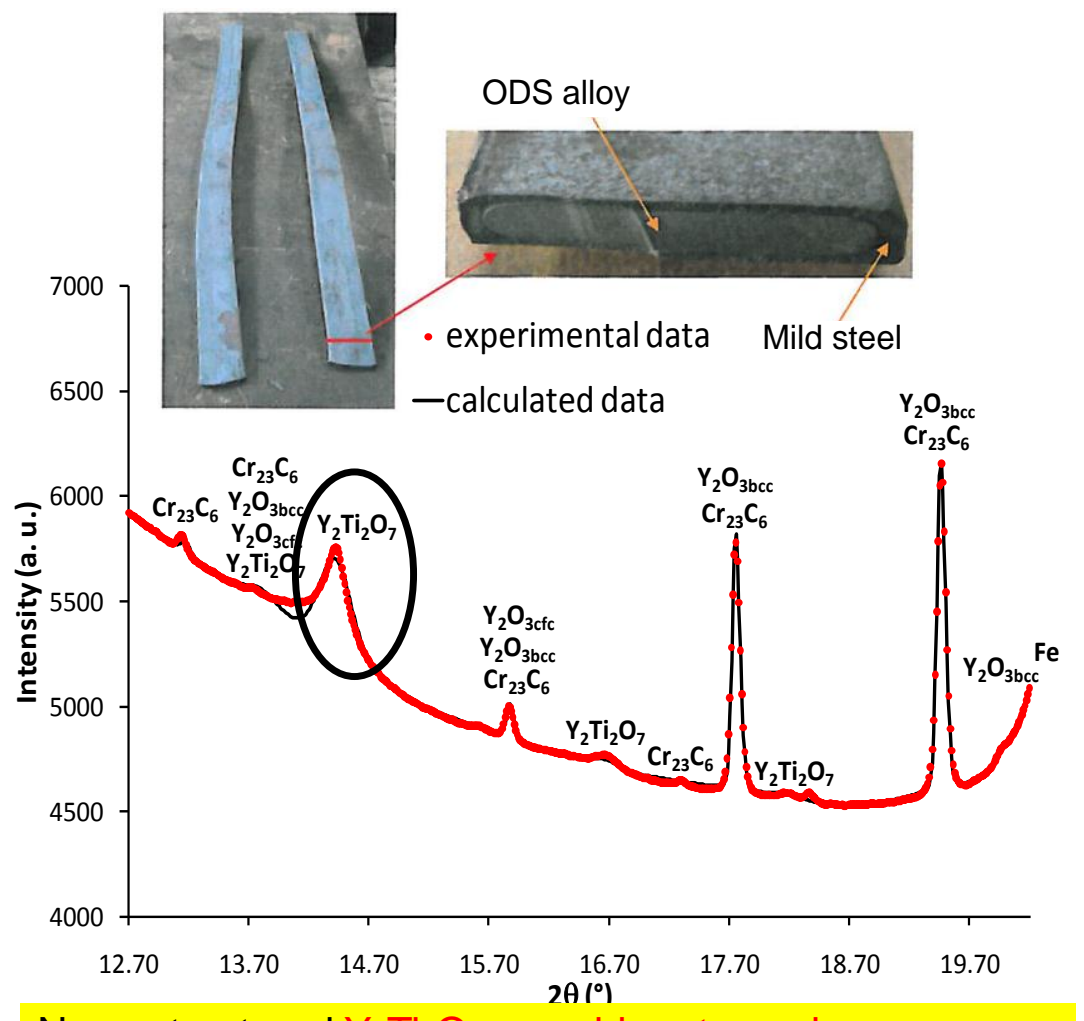

Nano structured $\mathrm{Y}_{2} \mathrm{Ti}_{2} \mathrm{O}_{7}$ pyrochlore type phase can be analyzed using XRD at MARS beamlline, cristallite sizing $\sim 15 \mathrm{~nm}$ (ML Lescoat et al. JNM 2012) 
$0^{\circ}$ MIN口S > For previous materials: in fluorescence mode at the $\mathrm{Y} \mathrm{K}_{\alpha}$-edge $(\mathrm{E} \sim 17.038 \mathrm{keV})$ in a He flow cryostat running at $\sim 10 \mathrm{~K}$
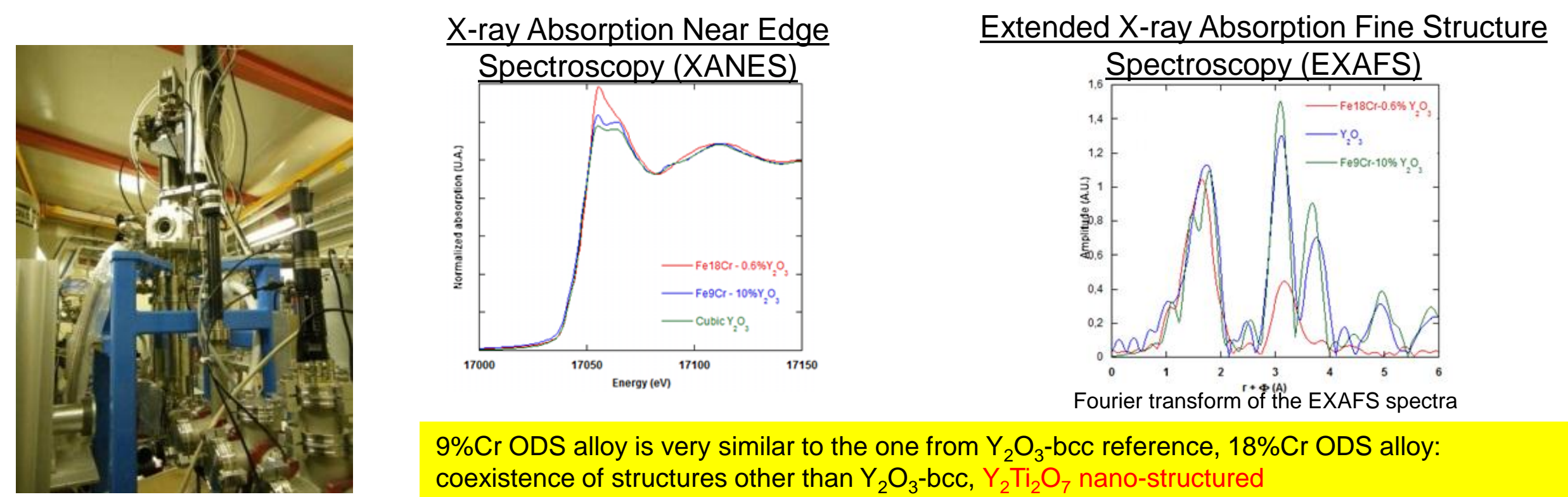

$9 \% \mathrm{Cr}$ ODS alloy is very similar to the one from $\mathrm{Y}_{2} \mathrm{O}_{3}$-bcc reference, $18 \% \mathrm{Cr}$ ODS alloy: coexistence of structures other than $\mathrm{Y}_{2} \mathrm{O}_{3}$-bcc, $\mathrm{Y}_{2} \mathrm{Ti}_{2} \mathrm{O}_{7}$ nano-structured

J-L Béchade et al. Journal of Nuclear Materials 428 (2012) 183-191

$>$ EXAFS spectra at $20^{\circ} \mathrm{C}$ on Fe-K edge $(7.112 \mathrm{keV})$

Fe18Cr1W0.8Ti+0.3MgO model alloy, after ion-irradiations (Jannus Saclay) at $500^{\circ} \mathrm{C}$ (ML Lescoat, 2012).

$\Rightarrow 50$ to $215 \mathrm{dpa}$ : quantitative analysis of the local atomic configuration as a function of irradiation dose work in progress 


\section{CONCLUSIONS AND PERSPECTIVES}

\section{MINDS}

CEA/DEN sponsoring the MARS beamline since the begining $=>$ first analyses for samples with activities < exemption limit (weakly activated materials) at room temperature using approved sample holders.

* Original results concerning secondary phases evolution under neutron irradiation ( $\mathrm{Zr}$ based alloys, M5 ${ }^{\mathrm{TM}}$ from 1 to 5 PWR cycles)

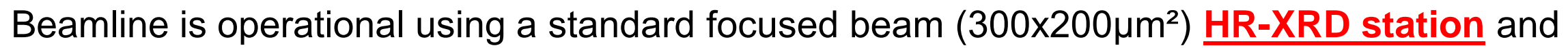
collimated beam $\left(50 \times 50 \mu \mathrm{m}^{2}\right)$ XAS station.

* HR-XRD station is in operation (irradiation defects have be quantified in Zr based alloy) ; adding off axis imaging plate geometry (excellent sensitivity) . T

* XAS station : Analyses using micro focused beam with KB optics $\left(10 \times 10 \mu \mathrm{m}^{2}\right)$ are available $=>$ local analyses and small quantity of material can be studied (ODS powder grain, $\mathrm{Zr}$ metal/oxide interfaces,...).

* XAS station : XANES and EXAFS from 10K to RT, before/after irradiation (demonstration from charged particles-Jannus-irradiated ODS steels => D. Menut PhD 2012-2015).

\section{Future:}

Beamline should be opened for samples with activities above the exemption level and for low and high temperature conditions after authorizations from the French Safety Authority (ASN), September 2013. 


\section{MIN口S}

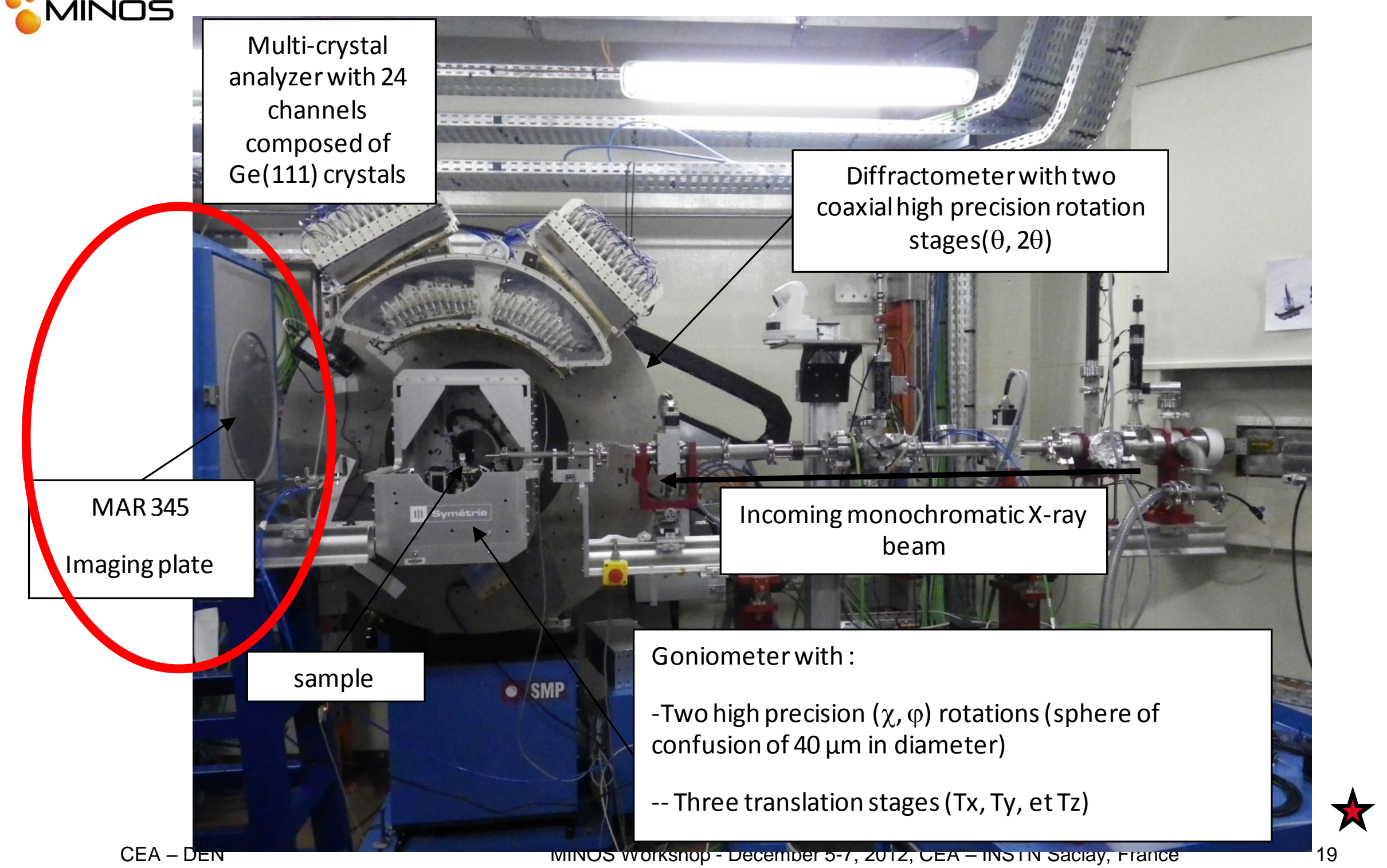




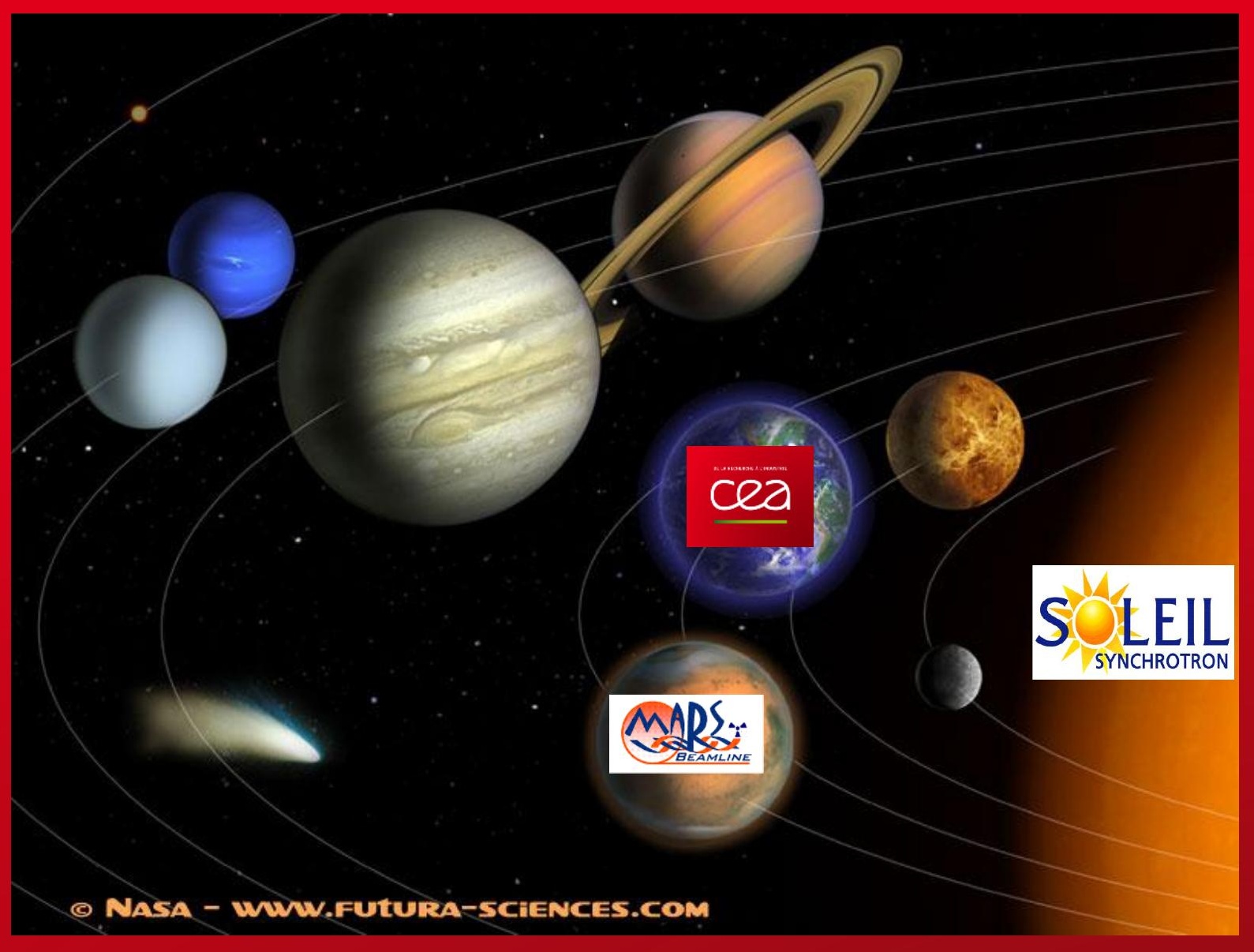

Commissariat à l'énergie atomique et aux énergies alternatives 